\title{
ASPECTOS SOCIOAMBIENTAIS DOS RESÍDUOS SÓLIDOS URBANOS DA CIDADE DE SÃO TOMÉ RN
}

\author{
AUCEMARA MAURÍCIO DOS ANJOS \\ aucemara10@gmail.com \\ JAIRO RODRIGUES SOUZA \\ jairo.souza@ifrn.edu.br
}

\section{RESUMO}

Os impactos causados pelo consumismo, a falta de sensibilização ambiental e de políticas públicas voltadas para este fim têm levado a reflexões e estudos sobre métodos e alternativas para minimizá-los, com o intuito de um dia eliminá-los. Mediante este contexto, este estudo tem como objetivo avaliar a percepção ambiental dos moradores da cidade de São Tomé/RN, tendo em vista que cidades pequenas também sofrem com o consumismo e com a destinação incorreta, seja por falta de orientação ou por falta de opção. Assim, esta pesquisa justifica-se por sua relevância para as políticas públicas, estratégias de gestão de resíduos sólidos a serem adotada, redução dos impactos socioambientais e econômicos do município, assim como para que outras pesquisas tenham informações que contribuam e enriqueçam o tema. Este estudo caracteriza-se como descritivo e exploratório, tendo como procedimento metodológico o estudo de caso. A coleta de dados foi feita inicialmente com embasamento teórico, com levantamento bibliográfico, e após pesquisa de campo com utilização de ferramentas de registro fotográficos e entrevistas com alguns moradores para avaliar a percepção deles em relação a coleta seletiva de São Tomé/RN. Como resultados, esta pesquisa identifica problemas relacionados à geração, destinação e ao armazenamento dos resíduos sólidos urbanos do município.

PALAVRAS-CHAVE: São Tomé RN. Resíduos Sólidos Urbanos. Sustentabilidade.

\section{DIAGNOSIS OF THE MANAGEMENT OF SOLID URBAN WASTE OF THE CITY OF SÃO TOMÉ RN}

\begin{abstract}
The impacts caused by consumerism, lack of environmental awareness and public policies aimed to this end have led to reflections and studies on methods and alternatives to minimize them, with the intention of one day eliminating them. In this context, this study aims to evaluate the environmental perception of residents of the city of São Tomé / RN, considering that small cities also suffer from consumerism and incorrect destination, either due to lack of orientation or lack of choice. Thus, this research is justified by its relevance to public policies, solid waste management strategies to be adopted, reduction of socio-environmental and economic impacts
\end{abstract}

of the municipality, as well as other research that has information that contributes and enriches the theme. This study is characterized as descriptive and exploratory, having as methodological procedure the case study. The data collection was done initially with a theoretical basis, with a bibliographical survey, and after field research using photographic registration tools and interviews with some residents to evaluate their perception in relation to the selective collection of São Tomé / RN. As results, this research identifies problems related to the generation, destination and storage of urban solid waste in the municipality. 


\section{INTRODUÇÃO}

No Brasil, segundo dados da Pesquisa Nacional de Saneamento Básico - PNSB (IBGE, 2002 e 2010), 59\% dos municípios brasileiros apresentavam em 2000 o lixão como destino final dos resíduos sólidos, estatística que caiu para 50,8\% em 2010.

Em 2010, foi sancionada a Política Nacional de Resíduos Sólidos (PNRS), considerada um avanço significativo na política ambiental brasileira (Brasil, 2010). Ao criar normas abrangentes para o gerenciamento de resíduos sólidos, a nova legislação responde a antigas demandas feitas não apenas por ecologistas, mas por toda a sociedade civil, diante do acúmulo exponencial de dejetos em áreas urbanas e rurais.

Atualmente, na cidade de São Tomé RN a situação parece não ser diferente de outras cidades interioranas brasileiras. Segundo a secretaria de obras, a cidade produz aproximadamente 40 toneladas semanais de lixo domiciliar que são despejados no lixão para a disposição final desses resíduos sólidos, como também, a cidade está inserida no consórcio entre municípios onde futuramente esses resíduos serão destinados ao aterro sanitário na cidade de São Paulo do Potengi, em média 45kms de distância da cidade.

O presente trabalho surgiu mediante a necessidade de se diagnosticar aspectos socioambientais relacionados ao gerenciamento dos resíduos sólidos urbanos da cidade de São Tomé RN.

Assim, esta pesquisa justifica - se por sua relevância para as políticas públicas, estratégias de gestão de resíduos sólidos adotadas, redução dos impactos socioambientais e econômicos do município, assim como para que outras pesquisas tenham informações que contribuam e enriqueçam o tema.

Objetivo geral

1.1. O objetivo geral deste estudo é diagnosticar o gerenciamento dos resíduos sólidos urbanos da cidade de São Tomé RN.

1.2. Objetivos específicos: Caracterizar os resíduos; fazer análise quantitativa dos resíduos; identificar aspectos e impactos da geração de lixo na cidade.

\section{REFERENCIAL TEÓRICO}

Para a ancoragem teórica deste estudo foi explorado o conceito da educação ambiental para a conscientização e sensibilização da sociedade de forma a contribuir para uma sociedade mais sustentável; contextualizar conceitos de 
gerenciamento integrado de resíduos sólidos urbanos, assim como sua caracterização e por fim, a política nacional de resíduos sólidos.

\subsection{Educação Ambiental}

Segundo García (2004)

O campo da educação ambiental se caracteriza pela diversidade. Não existe uma única concepção de educação ambiental e, apesar de esta diversidade ser enriquecedora, também dificulta a reflexão e a ação, por falta do consenso de um eixo de conhecimento de referência. Porém, em um aspecto todos estão de acordo: a educação ambiental pretende propiciar uma mudança de pensamento e a conduta das pessoas e dos grupos sociais; a divergência está em como se caracteriza esta mudança: seu sentido, seu conteúdo, as estratégias utilizadas, a amplitude da mudança proposta, entre diversos outros aspectos.

\subsection{Gerenciamento integrado de resíduos sólidos urbanos}

Estão sujeitas à observância da lei n 12.305/2010 todas as pessoas físicas ou jurídicas, de direito público ou privado, responsáveis, direta ou indiretamente, pela geração de resíduos sólidos e as que desenvolvam ações relacionadas à gestão integrada ou ao gerenciamento de resíduos sólidos.

A lei n 12.305, de 2 de agosto de 2010, é um recente marco regulamentar no país, instituindo a política nacional de Resíduos Sólidos. Esse instrumento traz uma série de definições, dentre elas, a logística reversa. Em seu artigo terceiro, inciso XII, define "logística reversa" como: "instrumento de desenvolvimento econômico e social caracterizado por um conjunto de ações, procedimentos e meios destinados a viabilizar a coleta e a restituição dos resíduos sólidos ao setor empresarial, para reaproveitamento, em seu ciclo ou em outros ciclos produtivos, ou outra destinação final ambientalmente adequada" (BRASIL, 2010).

\subsection{Política Nacional de Resíduos Sólidos}

A PNRS, em seu artigo $1^{\circ}$, evidencia os seus propósitos: disciplinar a gestão integrada dos resíduos sólidos, fazendo uso de princípios, objetivos e instrumentos que a viabilizem, atribuindo responsabilidade aos geradores, ao poder público e às pessoas físicas ou jurídicas responsáveis, direta ou indiretamente, pela geração de resíduos sólidos e as que desenvolvam ações relacionadas à gestão de resíduos sólidos. 
Há vários tipos de classificação dos resíduos sólidos que se baseiam em determinadas características ou propriedades identificadas. A classificação é relevante para a escolha da estratégia de gerenciamento mais viável. A norma NBR 10004, de 1987 trata da classificação de resíduos sólidos quanto a sua periculosidade, ou seja, característica apresentada pelo resíduo em função de suas propriedades físicas, químicas ou infectocontagiosas, que podem representar potencial de risco à saúde pública e ao meio ambiente. De acordo com sua periculosidade os resíduos sólidos podem ser enquadrados como:

\section{Classe I - Resíduos perigosos}

São aqueles que apresentam periculosidade, conforme definido anteriormente, ou uma das características seguintes: inflamabilidade, corrosividade, reatividade, toxicidade ou patogenicidade.

\section{Classe II -}

São aqueles que não se enquadram na classe I ou III. Os resíduos classes II podem ter as seguintes propriedades: combustibilidade, biodegradabilidade ou solubilidade em água.

\section{Classe III -}

São aqueles que, por suas características intrínsecas, não oferecem riscos à saúde e ao meio ambiente. Além disso, quando amostrados de forma representativa, segundo a norma NBR 10007, e submetidos a um contato estático ou dinâmico com água destilada ou deionizada, a temperatura ambiente, conforme teste desolubilização segundo a norma NBR 10006, não têm nenhum de seus constituintes solubilizados a concentrações superiores aos padrões de potabilidade da água, conforme listagem no 8, constante do Anexo H da NBR 10004, excetuando-se os padrões de aspecto, cor, turbidez e sabor.

Observou-se nesse tópico que, a PNRS lei 12.305/2010 norteou caminhos quanto a geração dos resíduos sólidos, coleta, armazenamento e a destinação final adequada dos resíduos perigosos. Como base estabeleceram procedimentos exatos para o gerenciamento dos resíduos do sistema da logística reversa. 


\section{METODOLOGIA}

O município de São Tomé RN está a $115 \mathrm{~km}$ de distância da capital Natal. Localizado na mesorregião Agreste Potiguar e na microrregião da Borborema Potiguar. De acordo com o censo realizado pelo IBGE no ano de 2018, sua população estimada é de 11.057 habitantes. Área territorial de $862,585 \mathrm{~km}^{2}$.

Figura 1 - Localização do Município de São Tomé no Mapa do RN

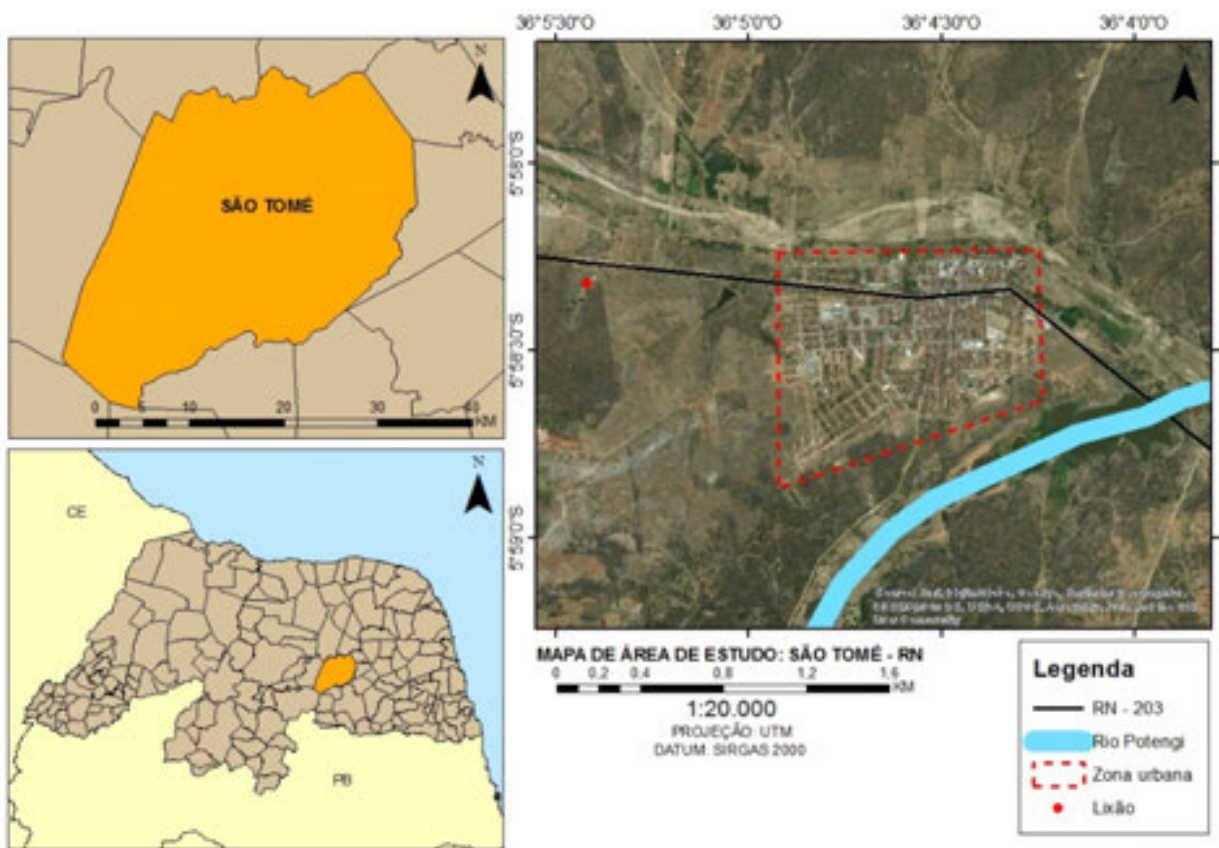

Figura 2: Fluxograma

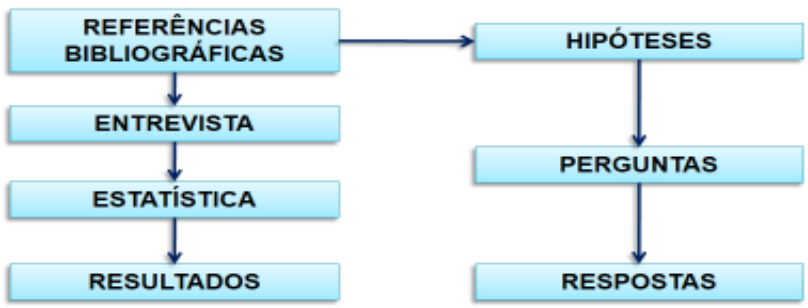

Este estudo caracteriza-se como descritivo e exploratório, tendo como procedimento metodológico o estudo de caso. A coleta de dados foi feita com 
embasamento teórico e após foram realizadas em média 10 visitas técnicas durante seis meses ao lixão e pelos bairros de São Tomé RN.

Para a complementação do diagnóstico, foram coletados dados em visitas de campo, nas quais se pretendeu consultar órgãos municipais responsáveis pela limpeza urbana e outros que favoreceu tais informações pertinentes ao estudo.

\section{RESULTADOS E DISCUSSÕES}

Verificamos que o que se refere a resíduos sólidos enfrenta sérios problemas para a gestão ambiental da cidade, tendo como foco a destinação final dos resíduos sólidos no município de São Tomé/RN e a maneira com que a população enxerga isso.

Como mencionado, os maiores problemas ambientais do Brasil estão na geração, além do destino e tratamento incorreto dos resíduos sólidos. Assim, percebeu-se que a quantidade de lixo gerado se dá pelo crescimento urbano e as transformações que ocorreram na sociedade.

A maioria da população de São Tomé RN, colocavam como alimento de animais (resíduo orgânico), pois não havia tanta embalagem, resíduos recicláveis, como é hoje. Com o tempo, o centro da cidade foi se urbanizando e a estrutura da sociedade foi sofrendo mudanças, sendo introduzida a cultura de consumo. Dessa forma, cada vez mais resíduos sendo gerados a solução encontrada foi a sua destinação em um terreno, o qual se encontra o lixão da cidade na atualidade.

De acordo com o roteiro da entrevista, dos entrevistados tem entre 14 e 65 anos de idade, destes possuem grau de instrução ensino fundamental, ensino médio e superior já completo. Foi diagnosticado que em média os entrevistados e moradores da cidade de São Tomé RN nos bairros do Centro, Potengi, Alto de São Sebastião e Bela Vista, não tem o conhecimento básico adequado sobre os resíduos sólidos e coleta seletiva. Outros não sabem do que se trata o assunto sobre geração, separação destinação e coleta seletiva correta dos resíduos recicláveis.

De acordo com o roteiro da entrevista, dos entrevistados tem entre 14 e 65 anos de idade, destes possuem grau de instrução ensino fundamental, ensino médio e superior já completo. 
Gráfico 1 - Faixa etária dos entrevistados

\section{Faixa etária dos entrevistados}

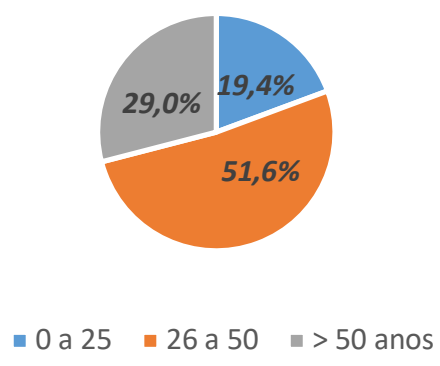

Fonte: Autoria própria, 2020.

Verificou-se nas entrevistas que são gerados vários tipos de resíduos como, plástico, papel, papelão, vidro, orgânico e outros.

Gráfico 2 - Resíduos gerados nas residências

\section{Resíduos gerados nas residências}

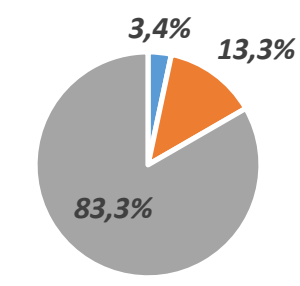

$$
\text { - Plástico } \quad \text { - Papel }
$$

Fonte: Autoria própria, 2020.

Percebemos que a população é bem assistida quanto aos recipientes para armazenamento na rua até o transporte de coleta seletiva fazer a retirada.

Gráfico 3 - As lixeiras de coleta seletiva atendem a sua rua?

\section{As lixeiras de coleta seletiva atendem} a sua rua?

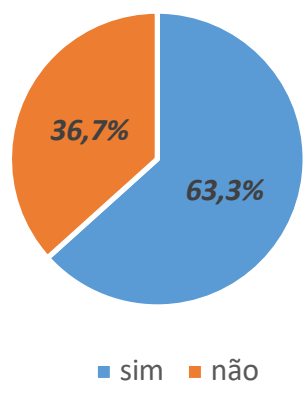

Fonte: Autoria própria, 2020. 
Em relação à separação dos resíduos informaram que destinam esses resíduos para coleta do município 3 vezes por semana onde são destinados ao lixão.

Quanto aos resíduos orgânicos a maioria informou que descartam para os animais domésticos, como alimento.

Gráfico 4 - Umidade dos resíduos sólidos

\section{Umidade dos resíduos sólidos}

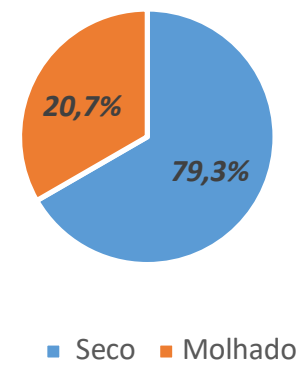

Fonte: Autoria própria, 2020.

Os transportes dos resíduos sólidos coletados são feitos por máquinas e veículos pertencentes à prefeitura ou alugados pelo órgão municipal. A distância média percorrida do ponto final da coleta até a unidade de transbordo, manejo ou destinação final é menor que $15 \mathrm{~km}$.

A única coleta seletiva na cidade é a coleta dos resíduos sólidos urbanos, os transportes são alocados pela gestão de serviços urbanos que são duas caçambas e dois tratores, durante três vezes por semana (segunda, quarta e sexta-feira), conforme ilustrado na fotografia 1.

\section{Fotografia 1 - Transporte da coleta seletiva de São Tomé RN}

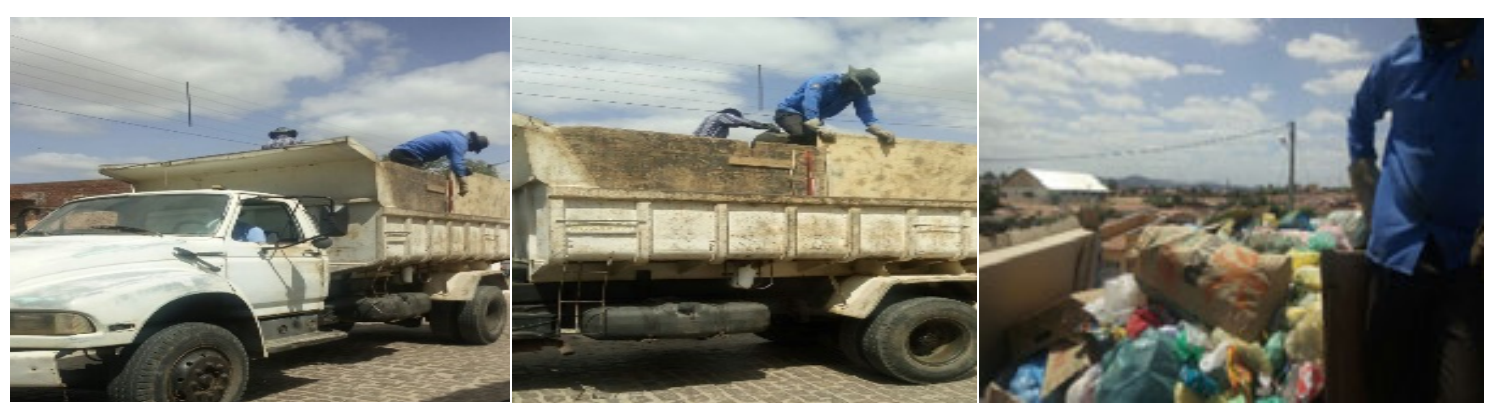

Fonte: Autoria própria, 2020.

Apesar de a destinação final ocorrer ao lixão a céu aberto, o município ainda possui uma coleta de resíduos convencional (mista), ou seja, sem que a população faça 
a separação do lixo orgânico (úmido) e não orgânico (seco), os resíduos ainda são coletados misturados.

Desse modo, necessita-se de um serviço de coleta especial para determinados resíduos, sendo esses os da construção civil (RCC); dos serviços de saúde (RSS); perigosos; dos serviços de capina; da roçagem; da varrição; de podas; e de desobstrução do sistema de drenagem, tendo em vista que podem oferecer incômodos e riscos à sociedade (BARROS, 2012).

Os resíduos sólidos urbanos gerados na cidade são destinados ao lixão do município (Fotografia 2), onde atuam duas famílias de catadores clandestinos. Lá, eles separam boa parte desses resíduos para reciclagem.

\section{Fotografia 2 - Lixão de São Tomé RN}

a)

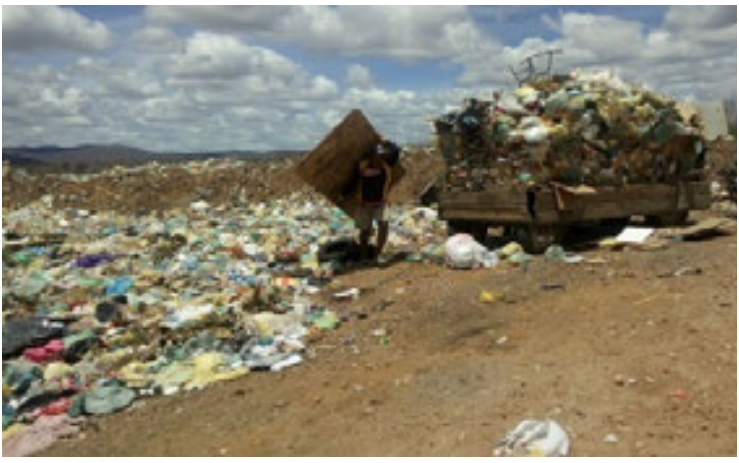

c)

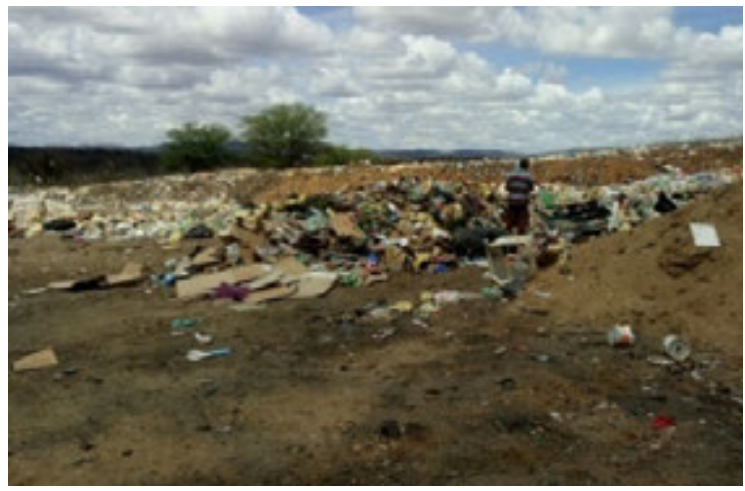

b)

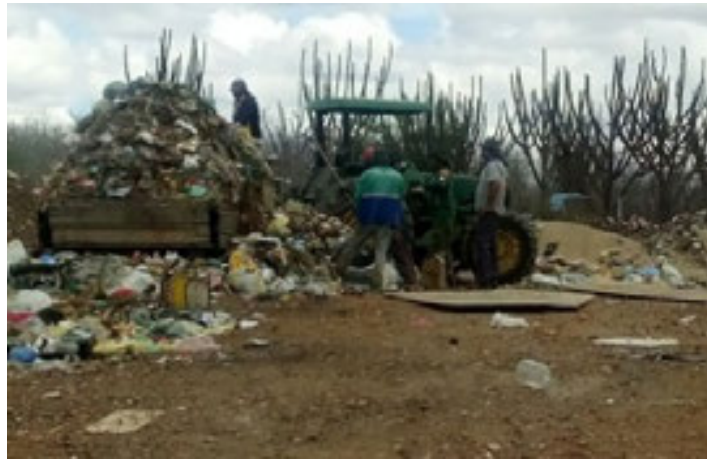

d)

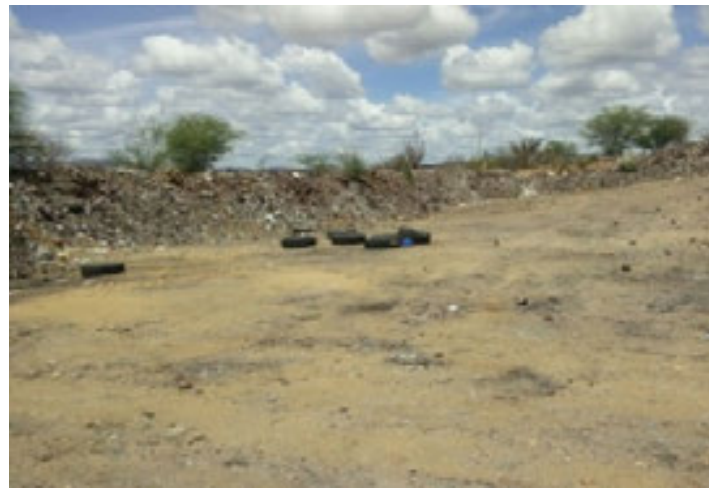

Legenda: (a) descarga dos resíduos no lixão, (b) aproximação dos catadores, (c) amostra do lixão e (d) Lixão. Fonte: Autoria própria, 2020.

Percebe-se a aproximação de catadores para fazerem a separação do lixo. A destinação final ocorre no lixão a céu aberto, a população ainda não tem o hábito e a educação ambiental adequada. Dessa forma, acaba não sendo feita corretamente, nas residências domésticas, a separação do lixo orgânico (úmido) e não orgânico (seco). 
Como também na cidade não existe nenhum projeto de incentivos a reciclagem e coleta seletiva desses materiais.

O levantamento realizado durante a elaboração do trabalho verificou a presença de cinco catadores na área de destinação dos resíduos. Também foi verificada a existência deles, dispersos pela cidade, em busca de materiais. Entretanto, não existe cooperativa formal dessa atividade.

De acordo com o estudo da composição gravimétrica de resíduos sólidos, São Tomé é um dos cinco municípios da região do Mato Grande com maiores frações de rejeito, com taxa superior a $20 \%$. Esse percentual denota a falta de prática da separação do lixo domiciliar um úmido e seco, ação simples que evita a contaminação dos resíduos que tem viabilidade de reciclagem ou reuso.

\subsection{Composição Gravimétrica dos Resíduos Sólidos}

O Plano Intermunicipal de Resíduos Sólidos da região do Mato Grande do estado do Rio Grande do Norte (PIRS - Mato Grande/RN), de 2016, fornece a composição gravimétrica de RS para São Tomé, indicada no Gráfico 1.

Gráfico 1 - Composição Gravimétrica dos Resíduos Sólidos Coletados no Município de São Tomé/RN

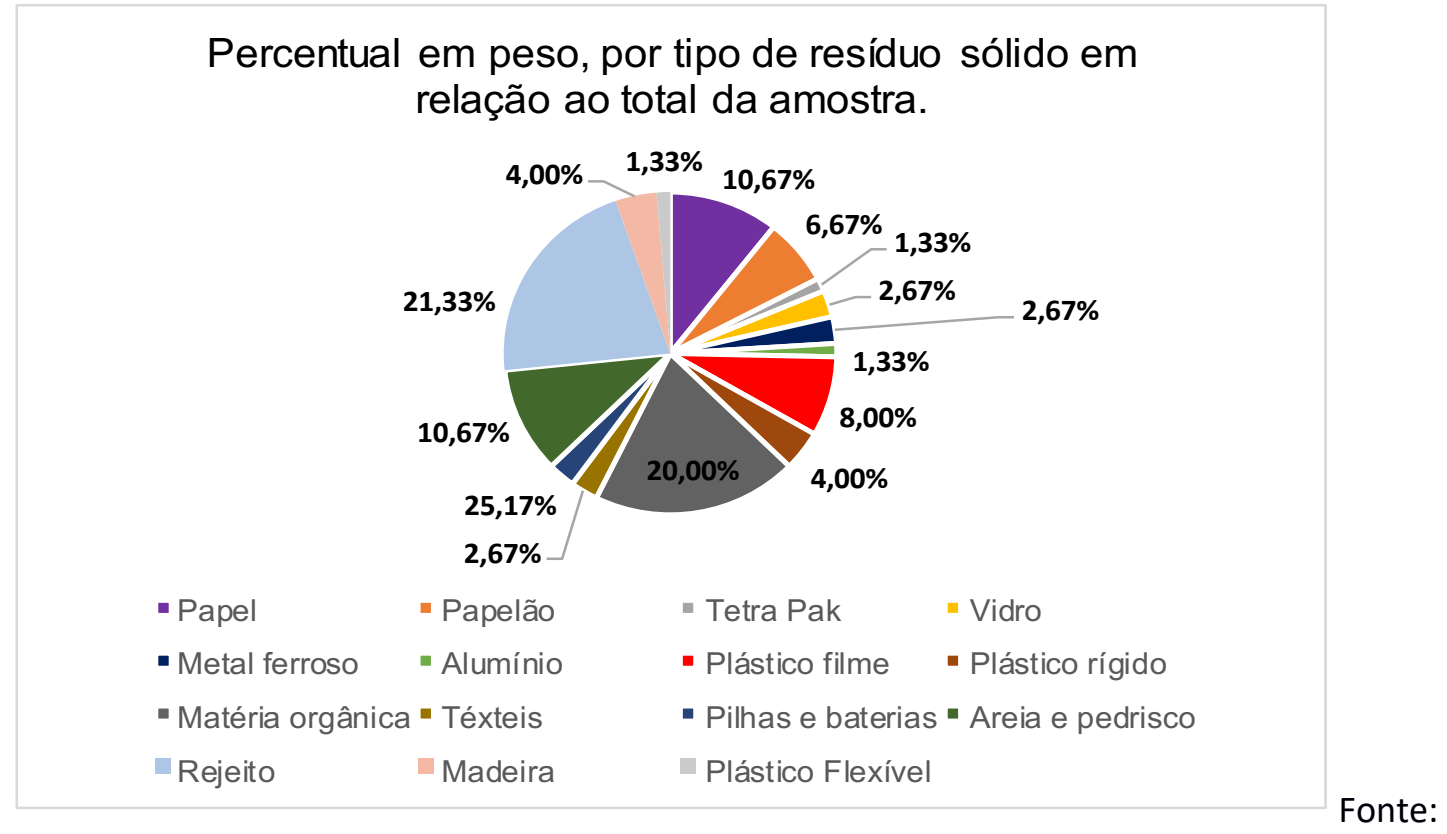

PIRS - Mato Grande/RN apud Brencorp (2016). 
A soma dos percentuais de resíduos recicláveis (plásticos, papelão, papel, metais, alumínio e vidro) é cerca de $37 \%$ da amostra, ou seja, um terço dos resíduos analisados tem potencial de reciclagem.

Nesses ambientes insalubres e sem controles sanitário e ambiental encontramse os catadores de materiais recicláveis, cujo número atual no país pode estar entre 300 mil e 1 milhão, segundo estimativa do Ministério do Desenvolvimento Social e de Combate à Fome, que coordena desde 2003 o Comitê Internacional de Inclusão Social de Catadores de Materiais Recicláveis (MDS, 2013).

Além disso, essa atividade de cooperativas pode proporcionar viabilidade econômica para grupos de catadores organizados que se encontram à margem do seu direito à cidadania, garantindo que eles participem formalmente de um mercado propenso a sofrer grande expansão no país, conforme é preconizado pela Lei no $12.305 / 2010$.

Vale salientar que boa parte desses resíduos é material reciclável, onde poderiam ser levadas em consideração a geração de emprego e renda do município, através de cooperativas de catadores de resíduos sólidos, parcerias municipais etc.

Existe uma defasagem em inclusão social e renda por meio de iniciativas de reciclagem, os quais poderiam incentivar ou até mesmo criar cooperativas de catadores de material reciclável no próprio município, assim como a implementação de uma pequena indústria de compostagem.

\section{CONSIDERAÇÕES FINAIS}

De acordo com a metodologia aplicada, são necessárias políticas públicas ligadas à área de meio ambiente na cidade de São Tomé RN, promovendo assim menor impacto ambiental, social e econômico e uma mudança positiva na qualidade de vida da população, fiscalizando e controlando a situação da poluição ambiental.

Faz-se necessárias parcerias, participação e sensibilização ambiental em toda população nas escolas, em casa, campanhas voluntárias nas ruas, comerciantes, feirantes, nos setores públicos e privados da cidade. Pois, a educação ambiental em conjunto com seus princípios e valores pessoais são fundamentais para as mudanças nos hábitos de vida das pessoas. 
Propõe-se como melhoria a adoção de oficinas de educação ambiental nas escolas e em eventos públicos para sensibilização da sociedade, assim como a adoção de um sistema de coleta seletiva composta por uma parceria entre a prefeitura e os catadores, estimulando a população para separação do lixo e adoção de práticas sustentáveis.

Além disso, há medidas que podem ser adotadas pelos órgãos públicos como a implantação da Agenda Ambiental da Administração Pública (A3P) que pode auxiliar aos órgãos em uma nova postura mais sustentável.

Diante desse contexto, percebe-se ainda que é necessário a sensibilização da comunidade para que eles participem separando o lixo para a destinação correta, como também ensinar técnicas de reaproveitamento dos resíduos sólidos e dos resíduos orgânicos para a comunidade.

Um convênio com o aterro sanitário controlado, a desativação do lixão local, a implantação da coleta seletiva e da reciclagem, implantação de pequeno eco pontos voluntários na zona urbana e rural, programas de educação ambiental e o mais interessante à sensibilização por meio de palestras e oficinas acabam sendo uma realidade necessária não apenas para o município de São Tomé, mas sim para todos os municípios brasileiros, pois é uma exigência prevista em Lei.

\section{REFERÊNCIAS}

ASSOCIAÇÃO BRASILEIRA DE NORMAS TÉCNICAS. NBR 10004. Resíduos sólidos: classificação. Rio de Janeiro, $2004 . \quad$ Disponível em: http://www.aslaa.com.br/legislacoes/NBR\%20n\%2010004-2004.pdf Acesso em 20 jan 2020.

ASSOCIAÇÃO BRASILEIRA DE NORMAS TÉCNICAS. 2004. Resíduos Sólidos - classificação: NBR-10004. Rio de Janeiro: ABNT 63p.

BARROS, Regina Mambeli. Tratado sobre resíduos sólidos: gestão, uso e sustentabilidade/ Regina Mambeli Barros. - Rio de Janeiro: Interciência; Minas Gerais: Acta, 2012. 374 p.

BRASIL. Lei no $\mathbf{1 2 . 3 0 5}$ de 02 de Agosto de 2010. Institui a Política Nacional de Resíduos Sólidos; altera a Lei no 9.605, de 12 de fevereiro de 1998; e dá outras providências. Disponível em: <http://www2.mma.gov.br/port/conama/legiabre.cfm?codlegi=636> Acesso em: 24 abr 2020. 
BRASIL. Ministério da Educação. Lei no 9.795 de 27/04/1999. Política Nacional de Educação Ambiental. Brasília, $1999 . \quad$ Disponível em: <http://www.planalto.gov.br/ccivil_03/Leis/L9795.htm> Acesso em: 23 abr 2020.

BRASIL. Presidência da República. Casa civil Lei n 12.305, de 2 de agosto de 2010. Disponível em: <http://www.planalto.gov.br/ccivil_03/_ato20072010/2010/lei//12305.htm.> Acesso em: 20 abr 2020.

GARCÍA, J. E. Educacíon Ambiental, constructivismo y complejidad. MontequintoSevilla: Díada Editora S.L, 2004.

INSTITUTO BRASILEIRO DE GEOGRAFIA E ESTATÍSTICA. IBGE. Disponível em: <https://cidades.ibge.gov.br/brasil/rn/sao-tome/historico> Acesso em: 20 abr 2020.

INSTITUTO BRASILEIRO DE GEOGRAFIA E ESTATístICA (IBGE). Pesquisa Nacional de Saneamento Básico. IBGE: Rio de Janeiro, 2002. 397 p.

INSTITUTO BRASILEIRO DE GEOGRAFIA E ESTATÍSTICA (IBGE). Pesquisa Nacional de Saneamento Básico. IBGE: Rio de Janeiro, 2010. 219 p.

Ministério do desenvolvimento social e combate à fome (MDS). BRASIL. Parceria entre governo e catadores de papel visa gerar trabalho e renda. Disponível em: <www2.ifrn.edu.br/ojs/index.php/HOLO/article/view/841/673> Acesso em 22 abr 2020

Secretaria do Meio Ambiente e dos Recursos Hídricos do Rio Grande do Norte. Plano Intermunicipal de Resíduos Sólidos da Região do Mato Grande do Estado do Rio Grande do Norte. Natal, 2016.146 p. 